\title{
Characterization of a New Copper Paste for Printed Electronics
}

\author{
Ihssan Hendi, ${ }^{1, *}$ Matthieu Blaise ${ }^{1}$, Gaétan Schneider ${ }^{1}$, Manuel Fendler ${ }^{1}$ \\ ${ }^{1}$ CEA Tech, 5 rue Marconi, Metz Technopole, 57070 METZ, France \\ *Corresponding author: E-mail: ihssan.hendi@cea.fr
}

DOI: $10.5185 /$ amlett.2020.061523

Printed electronics can be considered as an additive manufacturing technique allowing the fabrication of circuits and devices such as sensors, MEMS, LEDs, etc. An important research subject in this field is identifying new materials exhibiting low resistivity. In this article, we present a new copper paste interesting for structural electronics, based on additive manufacturing and laser activation. We characterized the structure of this copper paste after laser activation, by SEM, EDS, and FTIR. We also used four probe method to characterize sheet resistance to obtain a resistivity as low as $10^{-7} \Omega . m$, and compared it to other commercial conductive pastes.

\section{Introduction}

Additive Manufacturing (AM) has been finding more and more applications in the world of industry since the late $80 \mathrm{~s}$. Indeed, the definition of this process is the fabrication of objects through the deposition of a material layer by layer using a printing head, nozzle, or another printer technology [1]. One of the fields where industry profits from AM is the electronics field. The most well-known methods are screen printing [2], inkjet [2], aerosoljet [3] etc. Indeed, these methods use products such as conductive pastes, inks or powders to produce different micro objects such as sensors, RFID, MEMS, LEDS [4] etc. More precisely, a conductive paste or ink consists of different parts: the conductive metallic particles such as $(\mathrm{Cu}, \mathrm{Ag}, \mathrm{Au})$, Carbon NanoTubes (CNT), Graphene [4]. The polymer, which gives the adhesion property to the paste or ink. The solvent that provides the viscosity of the polymer/ink for the process. Lastly, an additive that allows keeping the structure of the paste/ink intact. After deposition, the ink/paste need a processing step by either sintering, UV light or laser in order to become conductive. The electrical performance of these materials after processing ranges from very low resistivity with Nano inks of copper, silver, graphene and carbon nanotubes $10^{-8} \Omega$.m [5-9], medium range between $10^{-7}-10^{-5} \Omega$.m for epoxy pastes, Table 2 , and at last semiconductor inks between $10^{-4}-10^{-2} \Omega$.m $[\mathbf{1 0}]$.

In the electrical conductors world, pastes and inks have a lower electrical performance than bulk metals [10] that are around $10^{-8} \Omega$.m. Although, their electrical performances still compares to alloys as Constantan $10^{-6} \Omega$.m [11] and Karma $5.10^{-7} \Omega$.m. Indeed such electrical performances are sufficient to certain basic electrical functions such as connections, antennas and resistances.

The combination of $\mathrm{AM}$ and conductive pastes is becoming more interesting since it can deposit these kinds of pastes and inks. This approach will allow electronics to move further from the traditional methods that use highly concentrated acids to deposit electrolytic copper. In fact, such acids are dangerous for humans and the environment. Furthermore, when we an AM approach, can avoid the mask steps needed to fabricate printed circuit boards, which simplifies the process and makes it cheaper [12].

In terms of application, the deposition of conductive pastes by AM addresses the mechanical and electronic coconception, which helps integrating sensors in industrial machines during their life cycle. Indeed, real time monitoring of tools and equipment in harsh environments (high pressure, temperature, vibrations and chocks), need embedded instrumentation performed by adding sensors to the industrial parts separately. This solution implies finding the place to add the sensors post fabrication, which is sub ideal. This is where AM has the advantage since electrical and mechanical co-design can optimize the topology of the piece allowing the direct integrating and packaging of the sensors in the same process.

In this article, we are taking the first step in this innovation by qualifying a paste that has a very good adhesion on a large variety of mechanical substrates. This paste becomes conductive under laser activation. We then observe the structure of the functional surface pre and post processing through SEM (Scanning Electron Microscope), EDS (Energy Dispersive X-ray Spectroscopy), and FTIR (Fourier Transformation InfraRed spectroscopy). Last, we evaluate its resistivity through four probe method and compare the results to other commercial pastes.

\section{Experimental}

\section{Material description}

We chose Eoprom $\odot$ paste (MCVE Technologie) which is a copper powder embedded in a polyurethane matrix. This structure gives the paste a viscosity of $6940 \mathrm{cps}$ at $20^{\circ} \mathrm{C}$. We decided to keep this viscosity as it is without any further dilution. The product is composed of 50-60\% of copper powder, $20-30 \%$ of polymer with some additives and 


\section{Advanced Materials Letters www. vbripress.com/aml}

solvents. The paste has good adhesion to FR4, polyaniline, metallic and glass substrates, which is the main reason behind our choice.

\section{Deposition}

We used micro-extrusion with nozzle as a method of deposition. Indeed, we equipped a 3D printer head with a syringe that we filled with the paste. The syringe is connected to a glue dispenser, Nordson ultimus V. We can choose the pressure through the glue dispenser from 1-7bars. The nozzles have a diameter that can range from $150 \mu \mathrm{m}-1 \mathrm{~mm}$. Four different parameters control the deposition on the printer. The diameter of the nozzle. The speed of the syringe displacement above the printer's chuck. The distance from the needle to the substrate and the pressure in the glue dispenser.

For our deposition, we filled the syringe with fresh paste and chose the following parameters for the deposition. Needle diameter $840 \mu \mathrm{m}$. Displacement Speed of $25 \mathrm{~mm} / \mathrm{s}$. Needle-substrate distance of $500 \mu \mathrm{m}$. A pressure of 3 bars. After one single displacement step, we obtained a track of $3250 \mu \mathrm{m} \pm 10 \mu \mathrm{m}$ large and a targeted length of $5 \mathrm{~cm}$. We shifted the head after each single track from $1 \mathrm{~mm}$. Thus, we have an overlap of $1000 \mu \mathrm{m}$ between the tracks in order to avoid as much as possible the ripples on the surface, estimated between 5 and $15 \mu \mathrm{m}$ on a total thickness of $1200 \mu \mathrm{m}$. We kept the deposition to dry out for $18 \mathrm{~h}$ to let the solvent evaporate and the paste to dry.

We deposit the paste this way because we need specific dimensions in order to respect the conditions of the test in order to qualify the paste through the four probe method. More specifically, the sample should have the following dimensions. A conductive surface $40 \%$ thinner than the distance between probes. A vertical distance from the closest insolent of 2 times the distance between the probes. A horizontal distance of 5 times the distance between the probes. At last an equivalent distance between the probes. If these conditions are not respected, there are corrections factors that should be taken into account [13].

\section{Laser activation}

The laser is Sesame Laser Plasma 500 DC from Digit Concept that is conventionally used for electrical components deprocessing. The laser type is a $10 \mathrm{~ns}$ pulsed Ytterbium crystal. The infrared wavelength is $1064 \mathrm{~nm}$. The maximum power is 10 watt. The scanning speed ranges from $10 \mathrm{~mm} / \mathrm{s}$ to $10000 \mathrm{~mm} / \mathrm{s}$ with a frequency of 20-200 kHz.

What we imply by activation is the step of passing the paste from its natural insulation state into a conductive state after interacting with the laser beam. Throughout our activation, we chose to keep the following parameters: scanning speed of $10 \mathrm{~mm} / \mathrm{s}$, spot diameter $40 \mu \mathrm{m}$, frequency $200 \mathrm{kHz}$, overlap between scanning paths of $30 \mu \mathrm{m}$. We chose to variate the laser power from $0 \mathrm{~W}$ to $2 \mathrm{~W}$. Indeed, this choice was in order to favor a sintering approach to the paste. Furthermore, we found that when the power is weaker than 1.2 watt, the paste stays insolent. At greater power than 1.6, the surface starts to burn and carbonate, thus including the graphite, which decrease the conductivity of the activated surface. For these reasons, we decided to stay between 1.2 and $1.6 \mathrm{~W}$ for activation. The thermal energy can be expressed as a function of the power through the following equation (1):

$$
E_{\text {therm }}=\frac{P}{V * d}
$$

where $E$ is the irradiance of the laser $\left(\mathrm{J} / \mathrm{cm}^{2}\right), P$ is the power used (watt), $d$ is the diameter of the laser spot $(\mathrm{mm})$ and $V$ is the scanning speed $(\mathrm{mm} / \mathrm{s})$ [14]. Applied to our case, the thermal energy diffused on the surface ranges from $300 \mathrm{~J} / \mathrm{cm}^{2}$ at 1.2 watt to $400 \mathrm{~J} / \mathrm{cm}^{2}$ at 1.6 watt.

Another type of interaction occurs during this process, which is the photon-matter interaction. Each photon carries an energy equaling to equation (2):

$$
E_{\text {photon }}=h v=\frac{h c}{\lambda}
$$

where $E$ is the energy of each photon in electronvolt, $h$ is the constant of Planck in electronvolt.second, $\mathrm{c}$ is the speed of light meter/second and $\lambda$ is the wavelength (1064 in our case) in meter. In this case, the photons have the energy of $1,17 \mathrm{eV}$.

\section{Four probe method}

We used Coprico 4002 micro ohmmeter for our four probe test. This method allows us to calculate the sheet resistance of the layer we deposit and then access to the resistivity of the material. Indeed, sheet resistance is more of a characteristic of the deposit layer whereas the resistivity is the characteristic of the material itself. The main use of the test was to characterize the resistance of semiconductor layers but then it became a standard test in electronics for all kinds of conductive layers.

The four probes are two external probes that provide a current in the surface and two internal ones that measure the difference of potentials due to the resistance of the surface, Fig. 1.

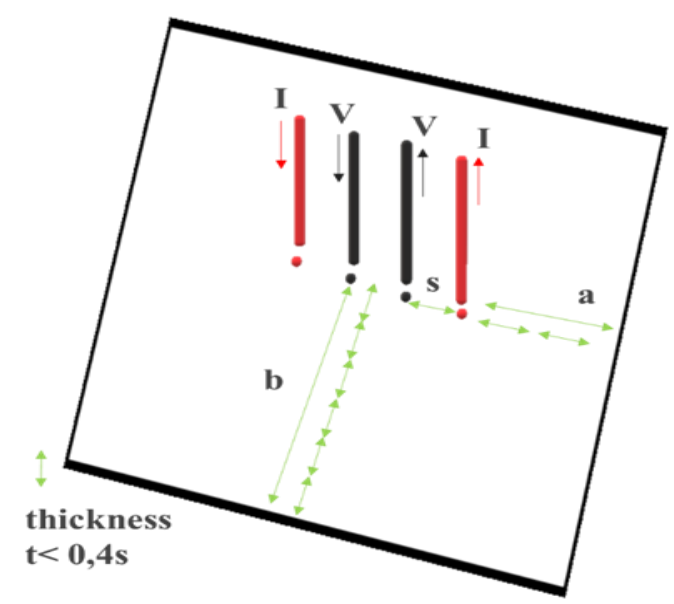

Fig. 1. A schematic of the step up for the four probe test. 


\section{Advanced Materials Letters www. vbripress.com/aml}

We can calculate the resistivity following the formula:

$$
\rho=\frac{V}{I} \frac{2 \pi}{\frac{1}{s_{1}}+\frac{1}{s_{3}}-\frac{1}{s_{1}+s_{2}}-\frac{1}{s_{2}+s_{3}}}
$$

Where:

$\mathrm{V}=$ floating potential difference between inner probes, $(\mathrm{V})$

$\mathrm{I}=$ current through the outer pair of probes (A)

$s_{1}, s_{2}, s_{3}=$ Distance between the probes $(\mathrm{cm})$

$\rho=$ resistivity in $\Omega$.cm

When the distance between the probes is equivalent, the expression becomes:

$$
\rho=\frac{V}{I} 2 \pi s
$$

In the special case where the thickness $(t)$ of the conductive layer is $40 \%$ lower than the distance between probes the expression becomes:

$$
\begin{gathered}
\rho=\frac{V}{I} \frac{2 \pi}{\ln (2)} * t=4,53 * \frac{V}{I} * t \\
\frac{\rho}{t}=4,53 * \frac{V}{I}
\end{gathered}
$$

Where:

$$
\frac{\rho}{t}=R_{\text {. }}
$$

$\mathrm{R} \mathbf{m}$ is defined as the sheet resistance $(\Omega / \mathbf{\square})[\mathbf{1 3}]$.

In our case, we estimated the conductive thickness after laser activation to be at $30 \mu \mathrm{m}$. Thus, we chose a distance between probes to be $2 \mathrm{~mm}$.

\section{Observations}

We used different technics to characterize the paste. The first one is a Jeol SEM microscope, JSM-7200F LV, with a resolution of $1 \mathrm{~nm}$ at $15 \mathrm{kV}$ and a magnification from $10 \times 1,000,000$ times. Indeed, SEM allowed us to observe the surface structure of the paste before and after activation. Furthermore, the SEM microscope is also coupled with Energy Dispersive X-ray spectroscopy EDS analysis, from Brucker, which allows to have the atomic composition of surfaces. At last, we used FTIR analysis to complete the EDS analysis. The equipment that we used is an ALPHA FTIR spectrometer with a spectral range of $375-7500 \mathrm{~cm}^{-1}$. FTIR allowed us to study the chemical effect of the laser on the surface of the paste before and after activation by observing the organic functions evolution on the surface. A typical FTIR is mainly a surface analysis, with a typical depth of beam interaction below $2 \mu \mathrm{m}$.

\section{Results and discussion}

\section{SEM/EDS observations}

We used SEM in order to observe the evolution of the microstructure before and after activation. Indeed, we observed the surface of different samples activated at different energies. When we observe the neutral surface at $0 \mathrm{~J} / \mathrm{cm}^{2}$ (Fig. 2(a)), we can notice that the particles are laying on the surface without any connection between them which is the reason behind the insulation. When we increase the activation to $300 \mathrm{~J} / \mathrm{cm}^{2}$, Fig. 2(b), we can see that some particles start to get closer but there is still some difference in contrast, which is the reason why the surface starts to conduct. At last, when we increase the activation to $400 \mathrm{~J} / \mathrm{cm}^{2}$, Fig. 2(c), the surface is more homogenous. Thus, through the visual observations we could conclude that the structure of the surface is a network of grains that get in contact under the effect of the laser activation. We suppose that the laser irradiation eliminates the polymer allowing the metallic particles to get in contact and conduct. We studied afterwards the difference between the neutral and the activated surface at different activation energies with EDS analysis. When we look at the atomic percentages of the neutral paste (Table 1 neutral) if we take a closer look, we can see that the copper is at $20 \%$ and the oxygen is at $10 \%$, which suggests a copper oxide of $\mathrm{Cu}_{2} \mathrm{O}$ majority in order to get the right stoichiometry. When we start activating the surface, Table $1,300-400 \mathrm{~J} / \mathrm{cm}^{2}$, we can notice that the rations of carbon and oxygen atoms decrease, whereas the ration of copper atoms increases.

Table 1. The atomic percentages obtained by EDS analysis of the different activated surfaces.

\begin{tabular}{c|c|c|c}
\hline $\begin{array}{c}\text { Laser energy } \\
\left(\mathbf{J} / \mathbf{c m}^{2}\right)\end{array}$ & \%C (atom) & \%O (atom) & \% Cu (atom) \\
\hline Neutral & $67 \%$ & $10 \%$ & $23 \%$ \\
\hline 300 & $41 \%$ & $7 \%$ & $52 \%$ \\
\hline 325 & $30 \%$ & $7 \%$ & $62 \%$ \\
\hline 350 & $26 \%$ & $7 \%$ & $67 \%$ \\
\hline 375 & $24 \%$ & $7 \%$ & $69 \%$ \\
\hline 400 & $26 \%$ & $7 \%$ & $67 \%$ \\
\hline
\end{tabular}

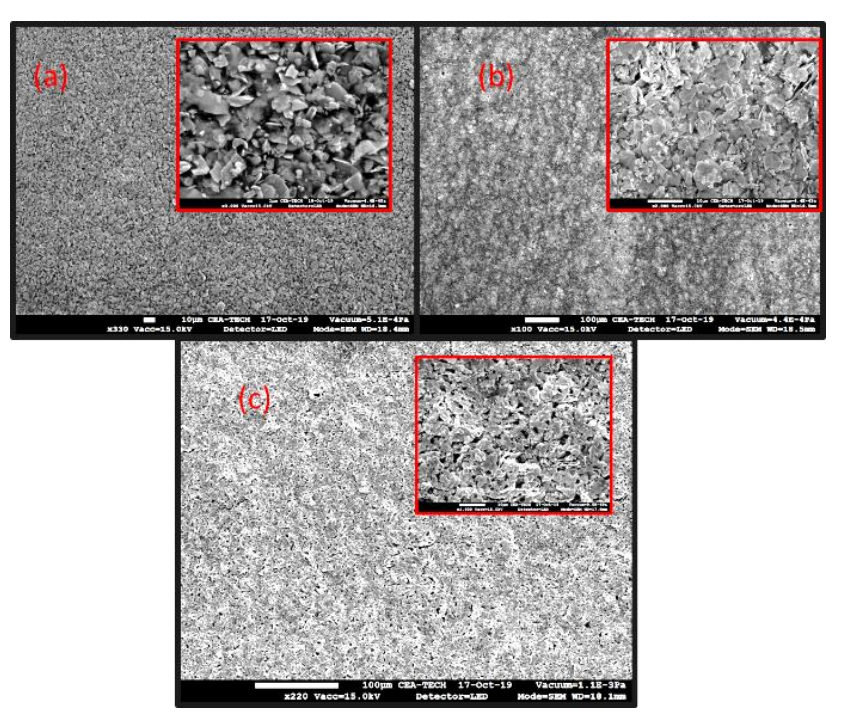

Fig. 2. Different SEM Images of the surface of different surfaces activated at (a) $0 \mathrm{~J} / \mathrm{cm} 2$ (b) $300 \mathrm{~J} / \mathrm{cm} 2$ (c) $400 \mathrm{~J} / \mathrm{cm} 2$.

Which suggests that the laser beam has a double effect on the paste: The first one being the elimination of the organic material due to the concentrated energy, which we observe by the decrease of the quantity of carbon. The second one being a reduction of the copper oxide in the paste into a metallic copper due to the energy that the photons provide, $1.17 \mathrm{eV}$. This reduced metallic copper allows the flow of electrons. In fact, some studies showed in literature that under the effect of UV light pulsed energy, providing an energy of $10 \mathrm{~J} / \mathrm{cm}^{2}[\mathbf{1 5}, \mathbf{1 6}]$, copper oxide became metallic copper. In our case, since we provide an 


\section{Advanced Materials Letters www. vbripress.com/aml}

energy of 300-400 J/cm ${ }^{2}$ and $1.17 \mathrm{eV}$ but to microparticles. We can only imagine that the copper oxide micro particles absorb the energy of the photons and become metallic particles. On the other hand, the polymer evaporates due to the heat. We suppose that the rest of oxygen atoms are the residue of the $\mathrm{CO}$ bind of the polymer and some copper oxide that was not reduced.

We completed the EDS analysis with FTIR spectroscopy in order to observe the disappearance ofthe organic functions in the paste (Fig. 4). In the neutral state, we observe the characteristic peaks of polyurethane functions, especially: $\mathrm{CO}, \mathrm{NH}, \mathrm{COC}$ and the $\mathrm{COO}$. When we increase the activation energy we can observe that the peaks still appear on the spectrum until $350 \mathrm{~J} / \mathrm{cm}^{2}$, After $400 \mathrm{~J} / \mathrm{cm}^{2}$, they completely disappear. At last, on a carbonized surface, corresponding to a $525 \mathrm{~J} / \mathrm{cm}^{2}$ activation energy, the spectrum corresponds to a baseline, which implies that the laser degraded the integrity of the polymer from the surface. The FTIR analyses concluded that the laser degrades the functions of the urethane that are polyols and isocyanate. When the laser power is sufficient, it eliminates the integrity of these functions, thus favoring a carbonization of the polymer residue.

We performed an EDS cartography on a $400 \mathrm{~J} / \mathrm{cm}^{2}$ activated sample in order to observe the homogeneity of the copper on the surface and to compare it to the non-activated surface (Fig. 3). We performed the EDS cartography around the borderline between activated and non-activated areas, and observed the disappearance of carbon on the surface as well as the majority of copper on the surface.

Thus, we obtain a complete degradation of the polymer from $300 \mathrm{~J} / \mathrm{cm}^{2}$ to $400 \mathrm{~J} / \mathrm{cm}^{2}$, where we obtain the highest percentage of copper mass and the tightest surface observations through SEM images.

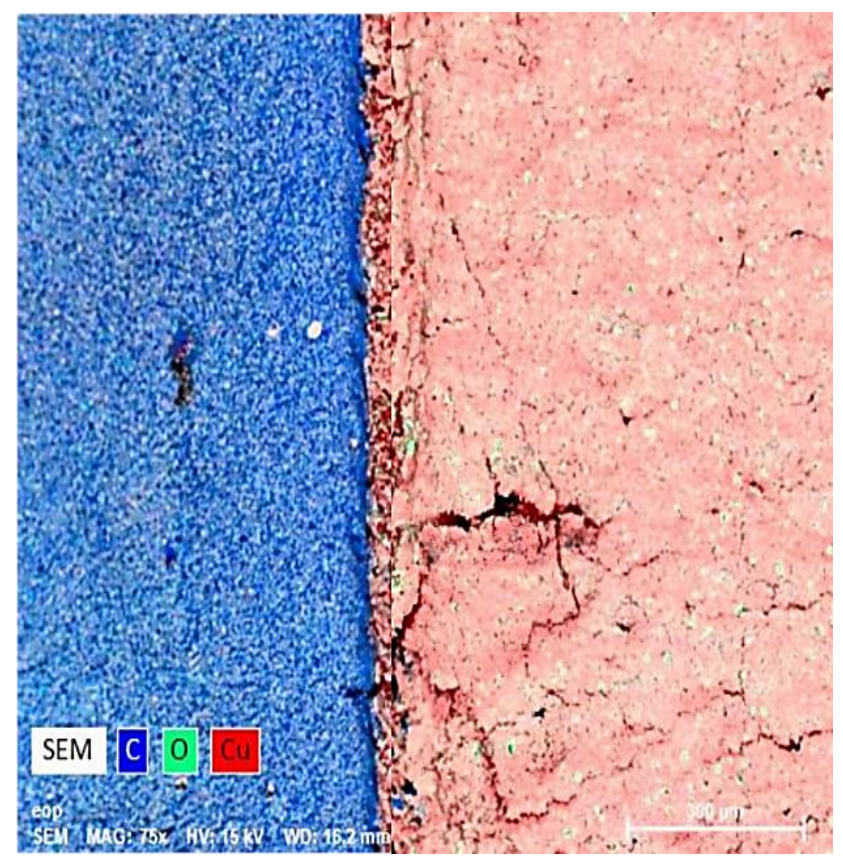

Fig. 3. EDS Cartography of the interface between the activated surface (right) and insolent surface (left).

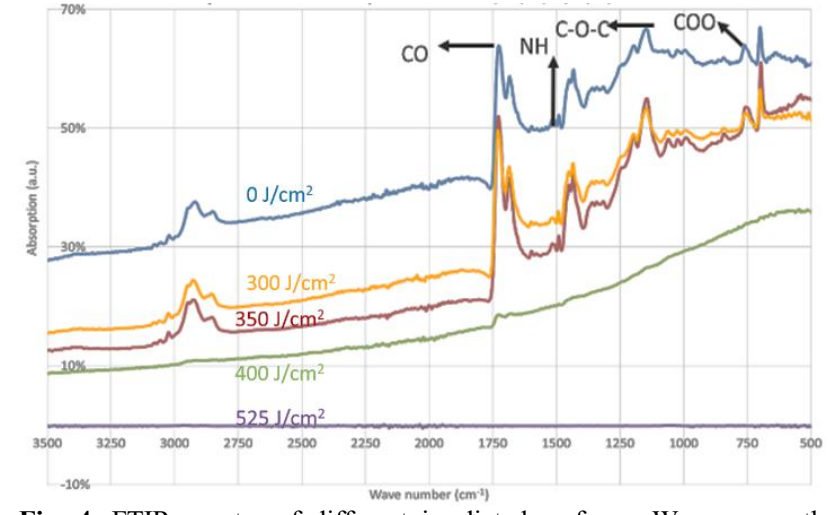

Fig. 4. FTIR spectra of different irradiated surfaces. We can see the different pics corresponding to the organic functions of the polymer

\section{Electrical characterization}

We studied the evolution of sheet resistance, independent of the depth of activation, by performing the four probe method mentioned above. We noticed a drop in the sheet resistance with the increase of laser power. The lowest sheet resistance at $400 \mathrm{~J} / \mathrm{cm}^{2}$, which is $22 \mathrm{~m} \Omega / \square$ (Fig. 5). This result correlates with the EDS analysis and FTIR spectra since we eliminate a considerable part of the polymer at $400 \mathrm{~J} / \mathrm{cm}^{2}$ laser power which allows the metallic copper micro-particles to have a better contact in-between and thus a lower resistance. At last, we evaluated the resistivity at $400 \mathrm{~J} / \mathrm{cm}^{2}$ since we obtained the lowest sheet resistance. In order to do that we need to observe the thickness of the sample. We observed with SEM an average thickness of $20 \mu \mathrm{m}$, with equation (5) we obtain a resistivity of $4.10^{-7} \Omega . \mathrm{m}$.

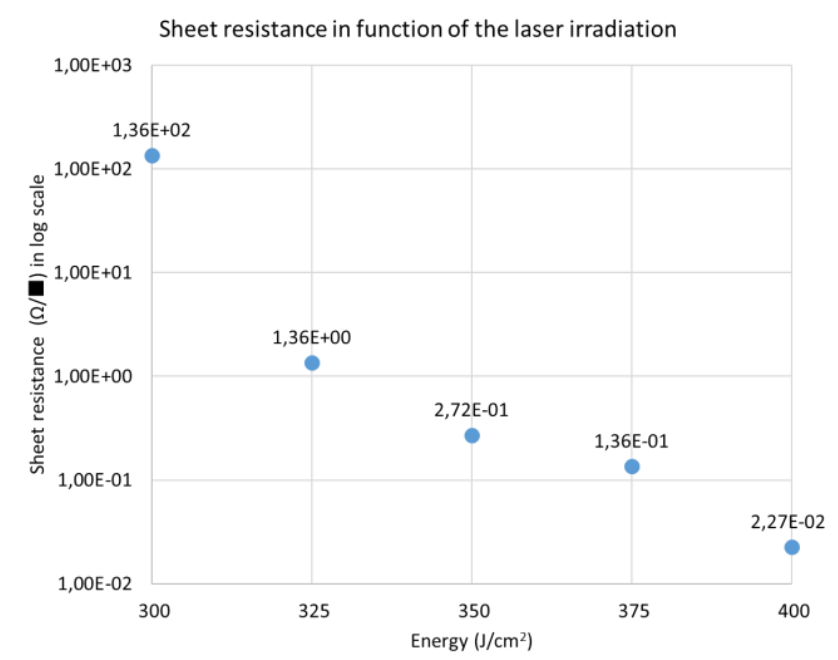

Fig. 5. The curve of the sheet resistance $(\Omega / \mathbf{D})$ in function of the irradiated energy in $\mathrm{J} / \mathrm{cm}^{2}$.

\section{Discussion}

We compared the result of our resistivity with available commercial pastes. These pastes are used in printed electronics for screen-printing, flexography printing or offset printing. Although the structure is the same (conductive micro- or nano-particles, polymer, solvent, 


\section{Advanced Materials Letters www. vbripress.com/aml}

additive), the electrical performances can vary according to the percentage of the conductive material, the particle size, the type of polymer, the process of activation etc. Through the commercial pastes that we identified ranging from $\left(10^{-5}-10^{-7} \Omega . \mathrm{m}\right)$, the average resistivity that we obtained with our process of activation position our new conductive paste higher than the state of the art (Table 2).

Table 2. A table of electrical performances of different types of material with a zoom on commercialized copper pastes.

\begin{tabular}{|c|c|c|}
\hline Material & Resistivity ( $\Omega . m$ ) & Family \\
\hline Silver & $1,50 \mathrm{E}-08$ & \multirow{8}{*}{ Conductors } \\
\hline Gold & $2,3 E-08$ & \\
\hline Copper & $1,68 \mathrm{E}-08$ & \\
\hline $\begin{array}{c}\text { Eoprom+electrolytic } \\
\text { copper }\end{array}$ & $3 E-08$ & \\
\hline Aluminium & $2,65 E-08$ & \\
\hline Tungsten & $5,60 \mathrm{E}-08$ & \\
\hline Nickel & $7,00 \mathrm{E}-08$ & \\
\hline Iron & $9,71 \mathrm{E}-08$ & \\
\hline $\begin{array}{c}\text { Constantan } \\
\text { (CopperNickel) }\end{array}$ & $4,00 \mathrm{E}-07$ & \multirow{3}{*}{ Conductors } \\
\hline $\begin{array}{c}\text { Karma } \\
\text { (Iron, chromium, Nickel) }\end{array}$ & $1,00 \mathrm{E}-06$ & \\
\hline Graphite & $1,00 \mathrm{E}-05$ & \\
\hline Germanium & $1-500 E-3$ & \multirow{2}{*}{$\begin{array}{l}\text { Semi- } \\
\text { Conductors }\end{array}$} \\
\hline Silicon & $0,1-60$ & \\
\hline Quartz & $7,50 E+17$ & Insolant \\
\hline
\end{tabular}

\begin{tabular}{|c|c|}
\hline Provider & Resistivity $(\Omega \cdot \mathrm{m})$ \\
\hline Eoprom & $2,00-6,00 \mathrm{E}-07$ \\
\hline NOF & $2,00 \mathrm{E}-07$ \\
\hline Dycotec & $2,00 \mathrm{E}-07$ \\
\hline Dycotec & $3,50 \mathrm{E}-07$ \\
\hline \multirow{3}{*}{ Tatsuta } & $1,00 \mathrm{E}-06$ \\
\cline { 2 - 2 } & $1,00 \mathrm{E}-06$ \\
\cline { 2 - 2 } & $1,00 \mathrm{E}-06$ \\
\hline Namics & $1,00 \mathrm{E}-06$ \\
\hline Harimatic & $1,00 \mathrm{E}-06$ \\
\hline IQ-BOND & $0,03-5,00 \mathrm{E}-06$ \\
\hline Hitachi & $2,00 \mathrm{E}-05$ \\
\hline
\end{tabular}

It is interesting to mention that the paste we used is traditionally used for screen printing and as base for electrolytic growth of copper in galvanic bath. The sheet resistance of the grown copper was $2 \mathrm{~m} \Omega / \boldsymbol{\square}$ with a resistivity of $3.10^{-8} \Omega . \mathrm{m}$ which is $50 \%$ of bulk copper performance.

\section{Conclusion}

We characterized a new copper conductive paste that we chose to use in our future applications for printed circuits and sensors. The main reason behind our choice was the high adherence to different material substrates. What we found interesting is that not only the electrolytic traditional use of the paste gives high electric performance $\left(3.10^{-8} \Omega . m\right)$. Furthermore, we were able to activate the paste and obtain a resistivity of $\left(4.10^{-7} \Omega . m\right)$, which is highly positioned compared to other conductive pastes. We concluded that under the activation of a pulsed Ytterbium crystal laser with a $1064 \mathrm{~nm}$ wavelength, thus an energy of $1.17 \mathrm{eV}$, and using energies between $300-400 \mathrm{~J} / \mathrm{cm}^{2}$, we were able to eliminate a big part of the polymer and reduce the copper oxide of the paste to conductive electrical copper.

\section{Acknowledgements}

This work was supported by Digitconcept that provided us with the laser. We would like to thank PFT plastinnov- IUT de Moselle-Est-Département chimie for providing the FTIR analysis.

\section{Keywords}

Copper conductive paste, laser activation, structural electronics, additive manufacturing.
Received: 31 October 2019

Revised: 23 December 2019

Accepted: 31 December 2019

\section{References}

1. American Society for Material and Testing (ASTM). Standard Terminology for Additive Manufacturing Technologies. Vol. F2792-12a. ASTM International, West Consholhocken, United States, 2009.

2. Handbook of print media technologies and production methods, Vol 1, Helmut Kipphan, Springer, Heidelberg Germany, 2001, pp55-63.

3. Wilkinson, N.J.; Smith, M.A.A.; Kay, R.W.; Harris, R.A.; The International Journal of Advanced Manufacturing Technology, Springer, 2019.

4. Kamyshny, Alexander; Magdassi, Shlomo; Chem. Soc. Rev.; 2019 , 48, 1712.

5. Kamyshny, A.; Ben-Moshe, M.; Aviezer S.; Magdassi, S.; Macromol. Rapid Commun.; 2005, 26, 281.

6. Park, J. H.; Jeong, S.; Lee, E. J.; Lee, S. S.; Seok, J. Y.; Yang, M.; Choi, Y.; Kang, B.; Chem. Mater.; 2016, 28, 4151.

7. Tobjörk, D.; Aarnio, H.; Pulkkinen, P.; Bollström, R.; Ma “' atta ”nen, A.; Ihalainen, P.; Ma kela", T.; Peltonen, J.; Toivakka, M.; Tenhu, H.; O"sterbacka, R.; 2012, 520, 2949.

8. Arapov, K.; Jaakkola, K.; Ermolov, V.; Bex, G.; Rubingh, E.; Haque, S.; Sandberg, H.; Abbel, R.; G. de With and Friedrich, H.; Phys. Status Solidi RRL, 2016, 10, 812.

9. Parekh, B. B.; Fanchini, G.; Eda, G.; Chhowalla, M.; Appl. Phys. Lett., 2007, 90, 121913.

10. Etienne Karmazsin, Techniques de l'ingénieur, Ref.: P1300 V2, 2001

11. Necyclopedic Dictionary of Polymers. Gooch J.W. Springer, Ney York, NY, 2207.

12. Eric Cadlen, Techniques de l'ingénieur, Réf. : E3342 V2 2005

13. Valdes, L. B.; Proceedings of the I.R.E, 420, 1954.

14. Tzeng, Y.F.; Int. J. Adv. Manuf. Technol.; 2000, 16, 10.

15. Matthew S. Rager; Tolga Aytug; Gabriel M. Veith; Joshi, Pooran; Applied Materials and Interfaces; 2015.

16. Ermak, Oleg; Zenou, Michael; Bernstein Toker, Gil; Ankri, Jonathan; Shacham-Diamand, Yosi; Kotler, Zvi; Nanotechnology; 2016, 27, 385201. 